(2) Open Access Full Text Article

\title{
Case of endophthalmitis following intravitreal injections of bevacizumab
}

This article was published in the following Dove Press journal:

Clinical Ophthalmology

10 July 2010

Number of times this article has been viewed

Shinya Komori'

Akira Sawada'

Tsutomu Oguni'

Kiyofumi Mochizuki'

Kiyofumi Ohkusu²

'Department of Ophthalmology, ${ }^{2}$ Department of Microbiology, Gifu University Graduate School of

Medicine, Gifu, Japan
Correspondence: Kiyofumi Mochizuki Department of Ophthalmology, Gifu University Graduate School of Medicine, I-I Yanagido, Gifu-shi 50 I-I I94, Japan

$\mathrm{Tel}+8 \mathrm{I} 582305287$

Fax $+8 I 582306289$

Email mochi-gif@umin.ac.jp
Purpose: We report a case of infectious endophthalmitis that developed after the third intravitreal injection of bevacizumab. The endophthalmitis was caused by Staphylococcus epidermidis.

Methods: Observational case series.

Results: This was a case of a 77-year-old man who had received three intravitreal injections of bevacizumab and developed infectious endophthalmitis. Polymerase chain reaction of an aqueous humor sample showed that the endophthalmitis was caused by S. epidermidis. The patient received intravitreal ceftazidime and vancomycin, and subconjunctival injection of vancomycin. After the intravitreal injections he was treated with topical levofloxacin and cefmenoxime hydrochloride, and intravenous cefpirome. Subsequently, the ocular inflammation gradually decreased and his visual acuity remained at 30/200.

Conclusions: Our findings indicate that endophthalmitis can develop after intravitreal bevacizumab injections. Polymerase chain reaction is useful for differentiation from sterile endophthalmitis.

Keywords: endophthalmitis, bevacizumab, Staphylococcus, antibiotics

\section{Introduction}

Intravitreal bevacizumab is now widely used to treat macular edema secondary to different pathological conditions including diabetic retinopathy, venous occlusive disease, and uveitis. However, infectious endophthalmitis can occur following any ocular surgical procedure including intravitreal injection. ${ }^{1}$ Noninfectious endophthalmitis after intravitreal injection sometimes shows similar symptoms such as sudden decreased vision. Therefore, it is important to make a prompt differentiation between infectious and noninfectious endophthalmitis.

We report a case of endophthalmitis that developed after the third intravitreal injection of bevacizumab. The endophthalmitis was caused by Staphylococcus epidermidis, which was identified by using polymerase chain reaction (PCR).

\section{Case report}

A 77-year-old man had undergone uncomplicated phacoemulsification with implantation of a posterior chamber intraocular lens (IOL) in both eyes followed by Nd:YAG laser posterior capsulotomy in his right eye. He was referred to the Gifu University Graduate School of Medicine on May 24, 2007 with a complaint of blurred vision in his right eye. He had suffered from systemic hypertension and diabetes mellitus. Our 
initial examination showed that his best-corrected visual acuity was 20/100 OD and 20/32 OS. Fundus examination revealed the scars of panretinal photocoagulation (PRP), and residual macular edema secondary to a central retinal vein occlusion in his right eye. He received two intravitreal injections of bevacizumab on May 31, 2007 and December 11,2007 , and underwent pars plana vitrectomy on March 5, 2008. Although his best-corrected visual acuity was restored to 20/40 in the right eye, ophthalmoscopy and by optical coherence tomography showed that the macular edema had recurred two months after the vitreous surgery. The patient did agree to a third intravitreal bevacizumab injection, which was given on October 14, 2008. Two days later the patient returned to our hospital complaining of decreased vision in his right eye. Examination showed that his best-corrected visual acuity was 20/200 in the right eye with mild ciliary injection and moderate nongranulomatous inflammation of the anterior chamber. Slitlamp examination also showed hypopyon and mutton-fat keratic precipitates (KP). The fundus of the right eye was not visible because of corneal folds and a moderate anterior chamber inflammation.

He was immediately admitted into our hospital and received intravitreal ceftazidime and vancomycin, and subconjunctival vancomycin. He was started on topical levofloxacin and cefmenoxime hydrochloride, and intravenous cefpirome (CPR). The ocular inflammation gradually decreased, but the intravenous antibiotic was continued for two additional weeks and then replaced by oral therapy. At three months, his best-corrected visual acuity remained at 30/200. Although cultures and broad-range PCR failed to detect any bacterial pathogens, the DNA of $S$. epidermidis was detected in the aqueous humor sample by PCR using each specific primer against $S$. aureus and S. epidermidis.

\section{Discussion}

The development of infectious endophthalmitis after an intravitreal bevacizumab injection has been reported. Fintak and colleagues describe three cases of endophthalmitis following an intravitreal injection of bevacizumab, and the incidence was calculated to be $0.02 \%$. $^{2}$ Two of their cases were caused by $S$. viridans and one by $S$. epidermidis. ${ }^{2}$ The incidence of endophthalmitis following intravitreal bevacizumab injection in large case series was reported to be 0.019 and $0.099 \% .^{3-5}$ Wickremasinghe et al reported the development of acute intraocular inflammation in 19 of $1278(0.1 \%)$ cases who had had an intravitreal bevacizumab injection. ${ }^{6}$
Five of the cases were severe, and cultures of the vitreous aspirate detected Propionbacterium acnes in two cases, coagulase-negative staphylococcus species in one case, and no microbial growth in two cases. Sterile endophthalmitis after repeated intravitreal injections of bevacizumab injection has also been reported. ${ }^{7}$ In our department, a total of 413 intravitreal injections of bevacizumab were undertaken between March 2007 and November 2009. Of those, only this case developed bacterial endophthalmitis following bevacizumab intravitreal injections. No eyes had acute intraocular inflammation in our series. The incidence of endophthalmitis following intravitreal bevacizumab injection in our case series was $0.24 \%$, which was slightly higher than other reports. In our case that developed endophthalmitis, the prompt identification of $S$. epidermidis in the aqueous humor aspirate by PCR could lead to appropriate management.

The risk of infectious endophthalmitis is always a concern when an intraocular procedure is performed. An improvement of the sterilizing procedures should help minimize the adverse event. This includes both pre-, intra-, and postoperative procedures. ${ }^{8}$ In this instance, we supposed an inadequate sterilization as the possible source of infectious endophthalmitis. Thereafter special care is taken with the additional administration of topical antibiotics three days before the operation, the complete covering of eyelashes with a sterile drape, and the use of $5 \%$ povidone iodine for a few minutes before surgery. Our case demonstrates that endophthalmitis can develop after intravitreal injection of bevacizumab, and PCR is useful for differentiation from sterile endophthalmitis.

\section{Disclosure}

The authors report no proprietary or financial interest in any products used in this study.

\section{References}

1. Scott IU, Flynn HW Jr. Reducing the risk of endophthalmitis following intravitreal injections. Retina. 2007;27(1):10-12.

2. Fintak DR, Shah GK, Blinder KJ, et al. Incidence of endophthalmitis related to intravitreal injection of bevacizumab and ranibizumab. Retina. 2008;28(10):1395-1399.

3. Lee SH, Woo SJ, Park KH, et al. Serratia marcescens endophthalmitis associated with intravitreal injections of bevacizumab. Eye. 2010; 24(2):226-232.

4. Artunay O, Yuzbasioglu E, Rasier R, Sengül A, Bahcecioglu H. Incidence and management of acute endophthalmitis after intravitreal bevacizumab (Avastin) injection. Eye. 2009;23(2):2187-2193.

5. Mason JO 3rd, White MF, Feist RM, et al. Incidence of acute onset endophthalmitis following intravitreal bevacizumab (Avastin) injection. Retina. 2008;28(4):564-567. 
6. Wickremasinghe SS, Michalova K, Gilhotra J, Guymer RH, Harper CA, Wong TY, et al. Acute intraocular inflammation after intravitreous injections of bevacizumab for treatment of neovascular age-related macular degeneration. Ophthalmology. 2008(11);115:1911-1915.

7. Yenerel NM, Dinc UA, Gorgun E. A case of sterile endophthalmitis after repeated intravitreal bevacizumab injection. J Ocul Pharmacol Ther. 2008;24(3):362-363.
8. Kelkar A, Kelkar J, Amuaku W, et al. How to prevent endophthalmitis in cataract surgeries? Indian J Ophthalmol. 2008;56(5):403-407.

\section{Publish your work in this journal}

Clinical Ophthalmology is an international, peer-reviewed journal covering all subspecialties within ophthalmology. Key topics include: Optometry; Visual science; Pharmacology and drug therapy in eye diseases; Basic Sciences; Primary and Secondary eye care; Patien Safety and Quality of Care Improvements. This journal is indexed on

Submit your manuscript here: http://www.dovepress.com/clinical-ophthalmology-journal

\section{Dovepress}

PubMed Central and CAS, and is the official journal of The Society of Clinical Ophthalmology (SCO). The manuscript management system is completely online and includes a very quick and fair peer-review system, which is all easy to use. Visit http://www.dovepress.com/ testimonials.php to read real quotes from published authors. 